Gut, 1985, 26, 89-94

\title{
Influence of somatostatin and bombesin on plasma enteroglucagon and cell proliferation after intestinal resection in the rat
}

\author{
G R SAGOR, M A GHATEI, D J O'SHAUGHNESSY, M Y T AL-MUKHTAR, \\ N A WRIGHT, AND S R BLOOM
}

From the Departments of Medicine and Histopathology, Royal Postgraduate Medical School, London

SUMMARY The possible relationship between enteroglucagon and cellular proliferation in a rat model of intestinal adaptation after suppression and stimulation of enteroglucagon by somatostatin and bombesin has been investigated. Forty eight rats were divided into three groups of 16 animals, each group being further sub-divided into eight animals having intestinal resection and eight having intestinal transection. Group 1 was given somatostatin to suppress enteroglucagon, group 2 was given bombesin to stimulate enteroglucagon and group 3 (control group) had neither peptide. All animals were killed 12 days after operation. Circulating enteroglucagon and crypt cell production rate (CCPR) in the terminal ileum were measured. After administration of somatostatin (group 1) both CCPR and plasma enteroglucagon were lower after resection than controls (group 3$)(p<0.001)$. Transected rats receiving somatostatin showed a reduction in both plasma enteroglucagon and CCPR, but only the fall in enteroglucagon was statistically significant $(\mathrm{p}<0 \cdot 001)$. Transected rats receiving bombesin (group 2) had raised plasma enteroglucagon and CCPR compared with the control group (group 3 ) $(\mathrm{P}<0.005)$ but there was no significant further rise in these already raised parameters in resected animals. This study indicates that cell proliferation in the rat small bowel after surgery can be influenced by regulatory peptides. The changes in enteroglucagon corresponded closely with changes in CCPR, and this peptide remains a favoured candidate for the humorally mediated trophic influence on the small bowel.

The adaptive hyperplastic changes seen in the residual intestine after extensive small bowel resection have been shown to be closely related to oral nutritional intake following surgery. ${ }^{12}$ That luminal nutrition is the sole factor in initiating this response has been questioned and evidence is accumulating to suggest that a humoral mechanism may also be involved in this process. ${ }^{3-5}$ Gastrin was proposed as a candidate for such a role ${ }^{6}$ but this has not been substantiated ${ }^{78}$ and it now seems unlikely that gastrin has any major trophic effect on the small bowel. Furthermore, enteric mucosal hyperplasia has not been recorded in conditions of hypergastrinaemia such as the Zollinger-Ellison syndrome or pernicious anaemia. A number of other regulatory peptides have been investigated for a role

Address for correspondence: Professor S R Bloom, Department of Medicine, Royal Postgraduate Medical School, Du Cane Road, London W12 0HS.

Received for publication 16 March 1984 as an enterotropin in intestinal adaptation. Although cholecystokinin (CCK) and secretin given together to dogs on total parenteral nutrition prevented the villous hypoplasia associated with total parenteral nutrition, ${ }^{9}$ when each peptide was given separately to rats, no such effect was noted. ${ }^{10} \mathrm{n}$ During lactation, adaptive changes are seen in by-passed Thiry-Vella jejunal loops, suggesting that humoral factors may be responsible for these effects, ${ }^{12}$ and, although prolactin seemed an obvious candidate, this hormone has been shown not to play a part in bowel adaptation during lactation. ${ }^{13}$ Ornithine decarboxylase ${ }^{14}$ corticosteroids, ${ }^{15}$ epidermal growth factor ${ }^{16}{ }^{17}$ and hypothalamic/anterior pituitary hormones ${ }^{18}$ have all been investigated and shown to play a possible role in intestinal adaptation.

The report of an enteroglucagon producing renal tumour in a patient who exhibited small bowel 
thickening and increased villous height ${ }^{19} 20$ prompted the suggestion that this peptide may be a candidate humoral agent involved in intestinal adaptation. Further studies ${ }^{51-23}$ have provided additional circumstantial evidence that enteroglucagon is trophic to the small bowel. This study was, therefore, designed to investigate the enterocyte proliferation after small bowel resection and transection, under conditions of stimulation and inhibition of plasma enteroglucagon release by other gastrointestinal regulatory peptides.

\section{Methods}

\section{ANIMALS}

Forty eight male Wistar rats, weighing $200-250 \mathrm{~g}$ at the time of surgery, were used in the study. Diazepam and Hypnorm (fentanyl and fluanisone Janssen Pharmaceutical) by injection, were used as anaesthetic. Half of the rats had a $75 \%$ proximal small bowel resection, measured distally from the ligament of Treitz, while the other half had a jejunal transection immediately below the ligament of Treitz, with reanastomosis. Bowel anastomoses were fashioned with $6 / 0$ black silk. Animals were allowed water and food ad libitum. Food was in the form of pelleted rat diet (Labsure Animal Foods, Poole, Dorset). All animals were killed with ether 12 days after surgery as changes in CCPR reach a plateau at this time. ${ }^{24}$ Standard segments of small bowel (see below) were taken for estimation of crypt cell production rate and blood was taken by direct cardiac puncture for enteroglucagon radioimmunoassay. Both the food intake and the body weight changes over the duration of the experiment were measured daily.

Animals were divided into three groups of 16 , each group comprising eight rats with $75 \%$ proximal small bowel resection and eight rats with jejunal transection. Group 1 was given long-acting somatostatin (Des-AA ${ }^{12} 45_{12}{ }^{13}\left[\mathrm{D}\right.$-Trp ${ }^{8}$ ]-SS) ${ }^{25} 100 \mu \mathrm{g}$ per $100 \mu \mathrm{l}$ rat plasma subcutaneously twice a day for the last seven days of the experiment, a dose which preliminary experiments had suggested would approximately halve basal plasma enteroglucagon concentrations. Group 2 rats were given bombesin (Bachem Co, California) for a similar period. As this peptide is rapidly cleared after injection, it was administered continuously via the Alzet osmotic minipump, model 2001 (Scientific Marketing Associated, London), which was implanted subcutaneously in the back of the animals' neck under anaesthesia. Each pump, which delivers a constant flow at a rate of $1 \mu \mathrm{l} / \mathrm{hour}$ for seven days was filled with a solution of bombesin, $96 \mu \mathrm{g}$ per 100 $\mu l$ normal saline. This dose was ascertained in preliminary experiments to approximately double basal plasma enteroglucagon concentrations. Group 3 animals were given a minipump containing saline only over the last seven days of the experiment.

\section{CELL PROLIFERATION}

The crypt cell production rate (CCPR) was used as an index of cellular proliferation in the small bowel. Vincristine was used to arrest dividing cells in the metaphase so that the number of such cells could be counted. ${ }^{26}$ At 09.30 hours on the day of killing the animals, each rat was given vincristine sulphate (Oncovin, Eli Lilly \& Co Ltd, Basingstoke, UK) in a dose of $1 \mathrm{mg} / \mathrm{kg}$ body weight, by intraperitoneal injection. The first rat was killed 30 minutes after the injection and each subsequent animal was killed at 20 minute intervals thereafter. The ileocaecal valve was taken as a reference point and $20 \mathrm{~mm}$ lengths of bowel, at a fixed point $20 \mathrm{~mm}$ from the ileocaecal junction, were removed from each rat. The tissues were initially fixed in Carnoy's fluid for four hours and then transferred to $75 \%$ ethanol. The tissues were stained with Feulgen stain and the mucosa was stripped from the muscle coat. Individual crypts were then dissected out under the dissecting microscope. The number of metaphases in each crypt were counted and the mean of the metaphase counts of 10 crypts were taken as the reading for each individual rat. The number of cells arrested in metaphase per crypt was then plotted against time after vincristine administration. The crypt cell production per hour (CCPR) for the group is given by the slope of the regression line, fitted by method of least squares. ${ }^{27} 28$

\section{PLASMA ENTEROGLUCAGON}

Two assays were carried out, one for total glucagonlike immunoreactivity (R59) which reacts fully with pure porcine enteroglucagon (glicentin) and one for pancreatic glucagon, using a relatively specific Cterminally-reacting antiserum, RCS5, which gives zero readings in plasma after total pancreatectomy. ${ }^{29}$ The enteroglucagon concentration was then obtained by subtracting the small concentration of pancreatic glucagon from that of total glucagon. Changes of $10 \mathrm{pmol} / \mathrm{l}$ enteroglucagon in the plasma could be detected with $95 \%$ confidence.

\section{STATISTICAL METHODS}

The Student's $t$ test for paired data was used for the group analysis and results were expressed as a mean and standard error of the mean.

\section{Results}

FOOD INTAKE AND BODY WEIGHT

There was no significant difference in food intake 
per day between the three groups $(21 \pm 3 \mathrm{~g}, 23 \pm 2 \mathrm{~g}$, and $24 \pm 3 \mathrm{~g}$ respectively). At the end of the experiment all rats had regained their preoperative body weights, without significant differences occurring between the groups.

\section{CCPR AND PLASMA ENTEROGLUCAGON}

In the control animals (group 3) there was an increase in CCPR/h in the terminal ileum from $16.8 \pm 0.9$ in transected to $49.2 \pm 4.9$ in resected animals $(\mathrm{p}<0.001)$ (Table). Similarly, plasma enteroglucagon increased from $99.1 \pm 9.6 \mathrm{pmol} / 1$ in transected to $667 \pm 70 \mathrm{pmol} / \mathrm{l}$ in resected rats $(\mathrm{p}<0 \cdot 001)$.

After administration of somatostatin (group 1), rats with intestinal resection showed a fall in $\mathrm{CCPR} / \mathrm{h}$ to $15 \cdot 4 \pm 1.0$ compared with controls (group 3) $(\mathrm{p}<0.001)$ (Table). Similarly, there was a fall in plasma enteroglucagon after resection to $73 \pm 9$ $\mathrm{pmol} / \mathrm{l}$ compared with group $3(\mathrm{p}<0 \cdot 001)$. Although transected rats given somatostatin did show a fall in plasma enteroglucagon, $26 \cdot 3 \pm 8.9 \mathrm{pmol} / 1$ compared with group $3(\mathrm{p}<0.001)$, the change in CCPR was not significant.

After administration of bombesin (group 2) transected rats showed a rise in CCPR from $11.8 \pm 0.9$ in animals (group 3) to $24.5 \pm 1.9$ $(p<0.005)$ (Table). Similarly plasma enteroglucagon also rose from $99 \cdot 1 \pm 9.6 \mathrm{pmol} / \mathrm{l}$ in group 3 to $218 \pm 34$ $\mathrm{pmol} / \mathrm{l}(\mathrm{p}<0.005)$. Bombesin treated resected rats, however, showed no alteration in CCPR and plasma enteroglucagon, compared with group 3 resected animals.

\section{Discussion}

Although it seems certain that luminal nutrition is necessary for the adaptive response after extensive small bowel resection, ${ }^{2}$ there is considerable evidence that humoral mechanisms may also participate in the production of these changes. Thus the prevention of hypoplasia seen in isolated ThiryVella fistulae after jejunectomy ${ }^{3}$ and the adaptive changes in the ileum after colonic resection, ${ }^{30}$ where there is no change in the amount of nutrition reaching this part of the bowel, suggests that mechanisms, other than luminal nutrition, must be operative in these models. When two groups of intravenously-fed rats underwent either $75 \%$ proximal small bowel resection or jejunal transection, the resected rats showed a limited but significant increase in cell turnover in the residual bowel compared with transected animals, ${ }^{22}$ indicating that factors other than luminal nutrition must be responsible for these adaptive changes.

More direct evidence for a humoral mechanism in the adaptive process after small bowel resection is found in a study where rats were linked in vascular parabiosis for 48 hours. ${ }^{4}$ Transection and jejunal resection in one partner, resulted in a limited increase in uptake of tritiated thymidine in the unoperated parabiont, though this response was weaker than the direct changes seen in the resected animal.

Interest in enteroglucagon as a trophic agent in small bowel mucosa began with the finding of an enteroglucagon producing tumour in a patient who was found to have delayed gastrointestinal transit, gross thickening of the small bowel mucosa, with mucosal hyperplasia and an increase in the diamter of the bowel. ${ }^{19} 20$ These abnormalities reverted to normal after tumour resection with reduction of the plasma enteroglucagon concentrations. Furthermore, plasma enteroglucagon is markedly raised postprandially in a number of situations where there is also cellular proliferation in small bowel mucosa, such as untreated coeliac disease, ${ }^{31}$ after jejunoileal bypass $^{32}$ and after small bowel resection. ${ }^{33}$ The enteroglucagon producing cells have a distal distribution in the gut, being found in greatest concentration in the distal ileum, and to a lesser extent in the colon. ${ }^{34}$ These cells are stimulated directly by carbohydrates and long chain triglycerides ${ }^{35}$ and it has been suggested that in situations where proximal failure of absorption of nutrients occurs, such as after proximal small bowel resection, the enteroglucagon cells in the distal gut are stimulated by the relatively undigested chyme coming into contact

Table Plasma enteroglucagon concentrations and ileal crypt cell production rates (CCPR) in transected or resected rats receiving somatostatin, saline or bombesin (mean $\pm S E M, n=8$ ).

\begin{tabular}{|c|c|c|c|c|c|c|c|}
\hline & & \multicolumn{3}{|l|}{ CCPR } & \multicolumn{3}{|c|}{ Plasma enteroglucagon ( $\mathrm{pmol} / \mathrm{g})$} \\
\hline & & Transected & $p$ & Resected & Transected & $p$ & Resected \\
\hline Somatostatin & $p$ & $\begin{array}{l}15 \cdot 2 \pm 0 \cdot 7 \\
\mathrm{~ns}\end{array}$ & ns & $\begin{array}{l}15 \cdot 4 \pm 1 \cdot 0 \\
0.001\end{array}$ & $\begin{array}{l}26 \cdot 3 \pm 8 \cdot 9 \\
0 \cdot 001\end{array}$ & 0.001 & $\begin{array}{l}73 \pm 9 \\
0.001\end{array}$ \\
\hline Control & & $16 \cdot 8 \pm 0 \cdot 9$ & 0.001 & $49 \cdot 2 \pm 4 \cdot 9$ & $99 \cdot 1 \pm 9 \cdot 6$ & 0.001 & $667 \pm 70$ \\
\hline Bombesin & $\mathrm{p}$ & $\begin{array}{l}0.005 \\
24 \cdot 5 \pm 1.9\end{array}$ & 0.001 & $\begin{array}{l}\text { ns } \\
46 \cdot 7 \pm 3 \cdot 8\end{array}$ & $\begin{array}{l}0 \cdot 020 \\
218 \pm 38\end{array}$ & 0.001 & $\begin{array}{l}\text { ns } \\
708 \pm 82\end{array}$ \\
\hline
\end{tabular}


with them. This peptide may be responsible for stimulating enterocyte turnover and thus enhancing small intestinal absorptive capacity. ${ }^{36}$ This hypothesis is supported by strong circumstantial evidence in a number of models of adaptation, where good close correlation between circulating enteroglucagon concentrations and crypt cell production rate is seen. ${ }^{23}$ Both these parameters were equally influenced by the amount of orally ingested nutrients. ${ }^{22}$ When rats with isolated ThiryVella fistulae were nourished, either intravenously or orally, the latter group was found to have significantly less hypoplasia in the isolated fistula, with correspondingly greater plasma enteroglucagon concentrations ${ }^{5}$ and it is possible that the increased enteroglucagon released from the bowel of the orally fed rats was the circulating factor that helped to enhance cell turnover in the isolated loop. Long chain triglycerides given intragastrically have been shown to promote small bowel adaptation after resection in parenterally fed rats $^{37}$ and as triglycerides are one of the major stimuli for enteroglucagon release ${ }^{35}$ it provides further circumstantial evidence that this may play a part in bringing about these adaptive changes, although clearly, other mechanisms such as stimulation of the exocrine pancreas, ${ }^{38}$ the secretion of which appears to have a trophic influence on small bowel, ${ }^{39}$ may also be operating. Eight days after pancreatico-biliary bypass (PBD), plasma enteroglucagon concentrations were high, correlating with the adaptive bowel changes, while at three months after this procedure, although the degree of intestinal thickness was unchanged, the plasma enteroglucagon concentrations had fallen, ${ }^{40}$ suggesting that this peptide may be more important in initiating the adaptive response than maintaining it. The results of this study are, however, in contrast with the findings in a time course experiment, ${ }^{40}$ where rats with small bowel resection were studied at $1 \frac{1}{2}, 3$, $6,12,24$, and 48 days after surgery. Plasma enteroglucagon and CCPR were markedly raised at $1 \frac{1}{2}$ days and continued to rise in a closely correlated manner for the full period studied suggesting that at least in this model where cell production rate was measured, enteroglucagon may also be associated with the maintenance of the adaptive response.

In the present study, somatostatin and bombesin were administered over the last seven days of the study, these peptides having the effect of inhibiting (in the case of somatostatin) and stimulating (in the case of bombesin) enteroglucagon release. Because of the long acting nature of the somatostatin given, it was not necessary to administer this peptide by continuous pump infusion as was the case with bombesin. The dose of somatostatin was calculated for body weight from previous infusion studies of this peptide in man, ${ }^{41}$ while the bombesin dose was derived from the study in which $2.5 \mathrm{pmol} / \mathrm{kg} / \mathrm{min}$ of amphibian bombesin was found to stimulate the release of enteroglucagon ${ }^{42}$ and both were checked in pilot studies for their effect on enteroglucagon. Besides its effect on enteroglucagon, somatostatin has a wide range of inhibitory actions on other gastrointestinal functions, such as gastric and pancreatic secretion, gut motility, and blood flow, and the secretion of other peptide hormones. Likewise, the effects of bombesin are opposite to those of somatostatin, stimulating the various gastrointestinal functions mentioned above. There are, therefore, numerous mechanisms by which these two peptides could have had their effect on CCPR in this study. As the food intake in the three groups was similar, luminal nutrition was probably not responsible for these changes. Weight changes were not significantly different in the groups so it is unlikely that the major gastrointestinal functions were grossly impaired. It may well be, therefore, that the changes seen after somatostatin and bombesin administration could be mediated, at least in part, via their effect on enteroglucagon. Our data suggest that there may be a limiting concentration for CCPR and enteroglucagon, above or below which it is not possible to induce further changes, that is, stimulation with bombesin or suppression with somatostatin.

The results in this study, are in agreement with previous work, showing that shortening the bowel produces compensatory hyperplasia in the residual intestine and also supports the hypothesis that humoral factors may be operative. The mechanisms of intestinal adaptation are complex and multifactorial, with luminal nutrition, intestinal secretions and humoral factors probably all contributing. While it is possible that more than one humoral factor is implicated, the findings in this study suggest that enteroglucagon could be regarded as one of the favoured candidates, an interpretation also supported by the findings in another recent study, ${ }^{43}$ in which low dose partially purified rat enteroglucagon produced a $50 \%$ increase in a DNA synthesis in cultured guinea-pig jejunal mucosal cells. Direct infusion studies in animals, using a more purified enteroglucagon preparation, are now required to provide conclusive evidence as to the possible trophic role of enteroglucagon.

\section{References}

1 Dowling $\mathrm{RH}$, Booth CC. Structural and functional changes following small intestinal resection in the rat. Clin Sci 1967; 32: 139-49. 
2 Feldman EJ, Dowling RH, McNaughton J et al. Effects of oral versus intravenous nutrition on intestinal adaptation after small bowel resection in the dog. Gastroenterology 1976; 70: 712-9.

3 Williamson RCN, Bauer FLR. Evidence for an enterotrophic hormone compensatory hyperplasia in defunctioned bowel. Br J Surg 1978; 65: 736-9.

4 Williamson RCN, Buchholtz TW, Malt RA. Humoral stimulation of cell proliferation in small bowel after transection and resection in rats. Gastroenterology 1978; 75: 249-54.

5 Sagor GR, Al-Mukhtar MYT, Ghatei MA, Wright NA, Bloom SR. Evidence for a humoral mechanism after small intestinal resection. Exclusion of gastrin but not enteroglucagon. Gastroenterology 1983; 84: 902-6.

6 Johnson LR, Lichtenberger LM, Copeland EM et al. Action of gastrin on gastrointestinal structure and function. Gastroenterology 1975; 68: 1184-92.

7 Mayston PD, Barrowman JA, Dowling RH. Effects of pentagastrin on small bowel structure and function in the rat. Digestion 1975; 12: 78-84.

8 Morin CL, Ling V. Effect of pentagastrin on the rat small intestine after resection. Gastroenterology 1978; 75: 224-9.

9 Hughes CA, Bates T, Dowling RH. Cholecystokinin and secretin prevent the intestinal mucosal hypoplasia of total parenteral nutrition in the dog. Gastroenterology 1978; 75: 34-41.

10 Breuer R, Hatoff DE, Hughes CA, Dowling RH. Is CCK trophic to small bowel and/or pancreas? A study in rats during exclusive parenteral nutrition (EPN). Gut 1979; 20: 911.

11 Hughes CA, Breuer RS, Hatoff DE, Ducker DA, Dowling RH. The effect of CCK octapeptide on the pancreas: a study in rats during total parenteral nutrition (TPN) and oral feeding. [Abstract]. Eur $J$ Clin Invest 1980; 10: 16.

12 Elias E, Dowling RH. The mechanism of small bowel adaptation in lactating rats. Clin Sci Mol Med 1976; 51: 427-33.

13 Müller E, Dowling RH. Prolactin and the small intestine. Gut 1981; 22: 558-65.

14 Luck GD, Baylis SB. Ornithene decarboxylase in intestinal maturation, recovery and adaptation. In: Robinson JWL, Dowling RH, Riecken EO, eds. Mechanisms of intestinal adaptations. Lancaster: MTP Press, 1982: 65-78.

15 Batt RM, Peters TJ. Effects of prednisolone on the small intestinal mucosa of the rat. Clin Sci Mol Med 1976; 50: 511.

16 Dembinski A, Gregory H, Konturek SJ, Polanski M. Trophic action of epidermal growth factor on the pancreas and gastroduodenal mucosa in rats. $J$ Physiol (Lond) 1982; 325: 35-42.

17 Li AK, Schattenkerke ME, Huffman RG, Ross JS, Malt RA. Hypersecretion of submandibular saliva in male mice: trophic response in small intestine. Gastroenterology 1983; 84: 949-55.

18 Riecken EO, Menge $\mathrm{H}$, Bloch $\mathrm{R}$, Lorenz-Meyer $\mathrm{H}$, Warm K, Ihloff M. In: Dowling RH, Riecken EO, eds. Intestinal adaptation. Schattauer Verlag: Stuttgart, 1974: 239.
19 Gleeson MH, Bloom SR, Polak JM, Henry K, Dowling RH. An endocrine tumour in kidney affecting small bowel structure, motility and absorptive function. Gut 1971; 12: 773-82.

20 Bloom SR. An enteroglucagon tumour. Gut 1972; 13: 520-3.

21 Jacobs LR, Bloom SR, Dowling RH. Response of plasma and tissue levels of enteroglucagon immunoreactivity to intestinal resection, lactation and hyperphagia. Life Sci 1981; 29: 2003-7.

22 Sagor GR, Al-Makhtar MYT, Ghatei MA, Wright NA, Bloom SR. The effect of altered luminal nutrition on cellular proliferation and plasma concentrations of enteroglucagon and gastrin after small bowel resection in the rat. Br J Surg 1982; 69: 14-8.

23 Al-Mukhtar MYT, Sagor GR, Ghatei MA et al. The relationship between endogenous gastrointestinal hormones and cell proliferation in models of adaptation. In: Robinson JWL, Dowling RH, Riecken $\mathrm{EO}$, eds. Mechanisms of intestinal adaptation. Lancaster: MTP Press, 1982: 243-56.

24 Gornacz GE, Al-Mukhtar MYT, Ghatei MA, Sagor GR, Wright NA, Bloom SR. Plasma enteroglucagon and CCK levels: correlation with cell proliferation in defunctioned small bowel in the rat. Dig Dis Sci 1984. (In press).

25 Rivier J, Brown M, Vale W. D-Trp ${ }^{8}$-somatostatin: an analog of somatostatin more potent that the native molecule. Biochem Biophys Res Commun 1975; 65: 746-51.

26 Wright N, Watson A, Morley A, Appleton D, Marks J, Douglas A. The measurement of cell production rates in the crypts of Lieberkuhn. Virchows Arch [Pathol Anat] 1974; 364: 311-23.

27 Smith RS, Thomas DB, Riches AC. Cell production in tumour isografts measured using vincristine and colcemid. Cell Tiss Kinet 1974; 7: 529-36.

28 Camplejohn RS, Bone G, Aherne WA. Cell proliferation in rectal carcinoma and rectal mucosa, a stathmokinetic study. Eur J Cancer 1973; 9: 577-81.

29 Ghatei MA, Uttenthal LO, Christofides ND, Bryant MG, Bloom SR. Molecular forms of human enteroglucagon in tissue and plasma: plasma responses to nutrient stimuli in health and in disorders of the upper gastrointestinal tract. J Cin Endocrinol Metab 1983; 57: 488-95.

30 Wright HK, Poskitt KT, Cleveland JC, Herskovic TJ. The effect of total colectomy on morphology and absorptional capacity of the ileum in the rat. J Surg Res 1969; 9: 301.

31 Besterman HS, Bloom SR, Sarson DL et al. Guthormone profile in coeliac disease. Lancet 1978; 1: 785-8.

32 Bloom SR. Hormonal changes after jejuno-ileal bypass and their physiological significance. In: Maxwell JD, Gazet J-C, Pilkington TR eds. Surgical Management of obesity. London: Academic Press, 1980: 115-23.

33 Besterman HS, Adrian TE, Mallinson CN et al. Gut hormone release after intestinal resection. Gut 1982; 23: 854-61.

34 Bloom SR. Gut and brain - endocrine connections. $J R$ Coll Physicians 1980; 14: 51-7. 
35 Holst JJ. Extra pancreatic glucagons. Digestion 1978; 17: $168-90$.

36 Holst JJ, Sorensen TIA, Andersen AN et al. Plasma enteroglucagon after jejuno-ileal bypass with $3: 1$ or $1: 3$ jejuno-ileal ratio. Scand J Gastroenterol 1979; 14: 205-7.

37 Morin CL, Grey VL, Garofalo C. Influence of lipids on intestinal adaptation after resection. In: Robinson JWL, Dowling RH, Riecken EO, eds. Mechanisms of intestinal adaptation. Lancaster: MTP Press, 1982: 175-84.

38 Laugier R, Sarles H. Action of oleic acid on the exocrine pancreatic secretion of the conscious rat: evidence for an anti-cholecystokinin-pancreozymin factor. J Physiol (Lond) 1977; 271: 81-92.

39 Altman GG. Influence of bile and pancreatic secretions on the size of the intestinal villi in the rat. Am J Anat
1971; 132: 167-78.

40 Miazza B, Ghatei MA, Adrian TE, Bloom SR, Dowling RH. Are hormonal factors responsible for the intestinal and pancreatic hyperplasia of pancreaticbiliary diversion (PBD). [Abstract]. Regul Pept 1982; 3: 77.

41 Adrian TE, Barnes AJ, Long RG et al. The effect of somatostatin analogs on secretion of growth, pancreatic and gastrointestinal hormones in man. J Clin Endocrinol Metab 1981; 53: 675-81.

42 Ghatei MA, Jung RT, Stevenson JC et al. Bombesin: action on gut hormones and calcium in man. $J$ Clin Endocrinol Metab 1982; 54: 980-5.

43 Uttenthal LO, Batt RM, Carter MW, Bloom SR. Stimulation of DNA synthesis in cultured intestine by partially purified enteroglucagon. [Abstract]. Regul Pept 1982; 3: 84. 